\title{
Prognostic value of apoptosis inducing factor in uveal melanoma
}

\author{
V. KRASNIK ${ }^{1}$, A. FURDOVA ${ }^{1, *}$, Z. SVETLOSAKOVA ${ }^{1}$, D. KOBZOVA ${ }^{2}$, H. GERGISAKOVA ${ }^{2}$, L. FEKETEOVA ${ }^{2}$, M. SVETLOSAK ${ }^{3}$, A. BARTA ${ }^{4}$, P. BABAL ${ }^{2}$ \\ ${ }^{1}$ Department of Ophthalmology, Faculty of Medicine, Comenius University in Bratislava, Slovakia; ${ }^{2}$ Department of Pathology, Faculty of Medicine, \\ Comenius University in Bratislava, Slovakia; ${ }^{3}$ Department of Arrhythmias and Cardiac Pacing, National Institute of Cardiovascular Diseases, \\ Bratislava, Slovakia; ${ }^{4}$ Institute of Normal and Pathological Physiology, Slovak Academy of Sciences, Bratislava, Slovakia
}

*Correspondence: afrf@mail.t-com.sk, alikafurdova@gmail.com

Received February 23, 2016 / Accepted October 3, 2016

\begin{abstract}
In malignant tumors including uveal melanoma there is a continuous effort in search for additional and relevant factors with predictive value and possible therapeutic indications. In the present work we evaluated the 5-year mortality in a group of patients with surgically treated uveal melanoma and its relation to selected demographic, clinical and histopathological parameters, including the expression of apoptosis inducing factor (AIF) in the neoplastic tissue.

We analyzed retrospectively the clinical data of patients with uveal melanoma treated surgically (enucleation, endoresection, exenteration) in the period from 2001 to 2007 ( $n=54$ ). Immunohistochemical detection of AIF expression in formalin fixed and in paraffin embedded tissue samples was evaluated semiquantitatively, intensity and percentage multiplicative Quick Score (QS) was calculated and compared between patients with over 5 year $(n=32)$ and less than 5 year $(n=22)$ survival.

In the analyzed group of 54 patients the 5 year mortality was $41 \%$. We confirmed the negative prognostic significance of some of the known prognostic factors as the tumor size and volume, T3 and T4 stage in the TNM classification and the mixed histological type of the tumor. Immunohistochemistry performed on 49 melanoma specimens showed AIF cytoplasmic positivity, no nuclear translocation was detected. The cut-off value of AIF expression QS $\geq 4$ (18) in tumor cells separated the 5 year survival of patients $(P=0.018)$, odds ratio $5.2(1.24-21.73)$. Moderate and strong expression of AIF in tumor cells also correlated with less favorable prognosis. Confocal microscopy proved colocalization of AIF with mitochondrial marker in neoplastic cells.

The prognosis of patients with uveal melanoma can be more accurate with inclusion of immunohistochemical detection of AIF expression. Increased expression of the AIF protein appears as a new negative prognostic factor predicting the 5 year survival.
\end{abstract}

Key words: uveal melanoma, apoptosis inducing factor, prognosis

Uveal melanoma (UM) is the most frequent primary malignant intraocular tumor in adults. Despite of the progress in local therapy and its $90 \%$ success, no significant progress in extending the patient survival length had been achieved in the last decades [1]. The main cause of death of patients with UM is the metastatic dissemination that appears in up to $50 \%$ of patients at different time periods after the diagnosis had been established $[2,3]$. Today no effective therapy of UM metastases is known. The actual research is oriented on identification of patients with high risk for metastases development based on reliable prognostic factors and on development of adjuvant systemic therapy.

Despite high accuracy of diagnosis and availability of various methods of treatment, the mortality due to uveal melanoma has remained unchanged. The prognosis in uveal melanoma depends on clinical, histopathological and cytological factors. Clinical factors that relate to prognosis include location, size, and configuration of the tumor. Uveal melanoma can arise in the iris, the ciliary body or the choroid. Iris melanomas have the best prognosis and ciliary body melanomas have the worst prognosis. Based on retrospective studies, the mortality rates for uveal melanoma for comparable sized tumors treated by enucleation or other globe conserving methods such as radiotherapy appear to be similar. Histopathological factors such as cell type, mitotic activity, microcirculation architecture, tumor-infiltrating lymphocytes and the presence of extrascleral extension are also significant predictors of survival. More recently, cytological factors such 
as cell proliferation, cytomorphology, and molecular genetic prognostic markers have been identified with the hope of detecting high risk cases for adjuvant systemic immune therapy or chemotherapy. At present, the role of these therapeutic methods is not clearly established. Recent cytogenetic and molecular genetic research identified several genetic prognostic factors capable of making reliable predictions of prognosis in patients with uveal melanoma. While the cellular makeup of biopsied tumors remains very useful, recent discoveries in tumor cytology, gene expression profiling, and identification of circulating tumors cells have given more influence to cutting edge prognostic indicators.

It has been well established that there exists an association of uveal melanoma with monosomy 3 [4]. A retrospective study analyzing tumors in enucleated specimens demonstrated that no individuals with two copies of chromosomes 3 developed metastatic disease, however, $57 \%$ of those with monosomy 3 developed metastatic disease with a 3 year survival rate of $50 \%$ [5]. With this finding, direct tissue biopsy obtained via fine needle aspiration increased in popularity to offer screening for patients during therapeutic procedures for high-risk of metastasis. Patients found to have evidence for monosomy 3 were selected for adjuvant therapy or closer monitoring.

These genetic factors prove to be even more important predictors than clinical and pathological factors and have already been implemented in the current ocular oncology clinical practice.

Apoptosis inducing factor (AIF) is a protein with proapoptotic function in the nucleus and redox activity in mitochondria. The role of AIF in oncogenesis has been demonstrated in several experimental works [6, 7]. Expression of AIF and its potential prognostic significance in UM has not been explored yet. Uveal melanoma represents an important, so far not sufficiently investigated problem of oncoophthalmology. More exact prognosis and potential discovery of new therapeutic targets would be a great contribution to a better management of patients with this disease.

\section{Materials and methods}

A group of 54 patients who underwent surgical treatment (enucleation, endoresection, exenteration) for UM at the Department of Ophthalmology, Faculty of Medicine Comenius University in Bratislava in the period from Jan 12001 to Dec 31 2007, were included into the retrospective study. The size of the tumor was assessed based on ultrasound evaluation, CT or MRI investigation. The tumor volume was calculated with the formula: volume $=\pi / 6 \mathrm{x}$ length $\mathrm{x}$ width $\mathrm{x}$ height [8]. The patients were followed in the oncoophthalmology outpatient clinic in 6 to 12 months periods. The overall survival and appearance of metastases was evaluated to the date of Aug 312012.

After surgery the specimen was fixed and tissue samples were processed in paraffin and histologically evaluated by pathologists according to the WHO classification criteria [9].
Tissue microarray construction. According to tumor histology, one or two representative tumor areas were identified and marked on hematoxylin and eosin stained sections. Sections were matched to their corresponding wax blocks (the donor blocks), and 3-mm diameter cores of the tumor were removed from these donor blocks with the multipurpose sampling tool Harris Uni-Core (Sigma-Aldrich, Steinheim, Germany) and inserted into the recipient master block. The recipient block was cut into 5 - $\mu \mathrm{m}$ sections and sections were transferred to coated slides.

Immunohistochemical staining. Slides were deparaffinized and rehydrated in phosphate buffered saline solution (PBS; $10 \mathrm{mM}, \mathrm{pH}$ 7.2). The slides were subsequently incubated 1 hour at room temperature with primary anti-AIF rabbit polyclonal antibodies (Millipore, Darmstadt, Germany), diluted 1:100 in Dako REAL antibody diluent and immunostained with EnVision G/2 System/AP alkaline phosphatase Permanent Red visualization system according to the manufacturer's instructions (DAKO, Glostrup, Denmark). The slides were counterstained with hematoxylin and mounted. As a positive control for AIF, normal colon tissue was included. As negative control, the same tissue was used, with omitting the primary antibody from the staining protocol.

For evaluation of AIF localization in the cells, the slides were pretreated as above. The primary antibodies: anti-AIF rabbit polyclonal antibodies (Millipore) in concentration 1:500 and anti-mitochondrial mouse monoclonal antibody 1:500 (clone 113-1, Millipore), were mixed and incubated on the slide 1 hour at room temperature. After three $5 \mathrm{~min}$ washes in PBS, the slides were incubated with: goat anti-rabbit antibodies conjugated with AlexaFluor 594 diluted 1:200 in PBS and sheep anti-mouse antibodies conjugated with AlexaFluor 488 diluted 1:200 (Thermo Fisher, Waltham, MA USA), were mixed and incubated on the slide $30 \mathrm{~min}$ at room temperature. After three 5 min water washes, the slides were counterstained 5 min with DAPI diluted 1:1000 in distilled water, rinsed and mounted in fluorescence cover medium (DAKO). The slides were looked and digitally evaluated in 40' confocal microscope (Nikon, Kanagawa, Japan) with application of NIS-Elements Confocal software (Nikon).

Immunohistochemical stain scoring. Tumor cores were independently assessed by two observers (HG and PB) who were blinded to clinicopathological data. In cases of disagreement, the result was reached by consensus. AIF expression was scored by the multiplicative quick score method (QS), which accounts for both the extent of cell staining as well as staining intensity. Briefly, the portion of positive cells was estimated and given a score on a scale from 1 to 6 ( $1=1-4 \% ; 2=5-19 \% ; 3=20-39 \% ; 4=40-59 \% ; 5=60-79 \%$; and $6=80-100 \%)$. The average intensity of the positively staining cells was given a score from 0 to $3(0=$ no staining; $1=$ weak; $2=$ moderate; and $3=$ strong staining). Recalculated QS was done by multiplying the percentage score by the intensity score, to yield a minimum value of 0 and a maximum value of 18 [10]. 
Statistics. For statistical analysis purpose the patients were divided into two groups: those who died 5 years after surgery $(\mathrm{n}=22)$ and patients surviving over 5 years after surgery $(\mathrm{n}=32)$. Total mortality was evaluated. For statistical analysis were used the $\chi^{2}$ test, Fisher exact test, Manna-Whitney test, Kolmogorov-Smirnov, Student t-test and in survival evaluation the Kaplan-Meier analysis; the acquired lines were compared with the help of log rank test. Statistically significant was the value $p<0.05$.

\section{Results}

In the group of 54 patients, 26 males (48\%) and 28 women $(52 \%)$, the average age at the time of surgery was $63.9 \pm 13.7$
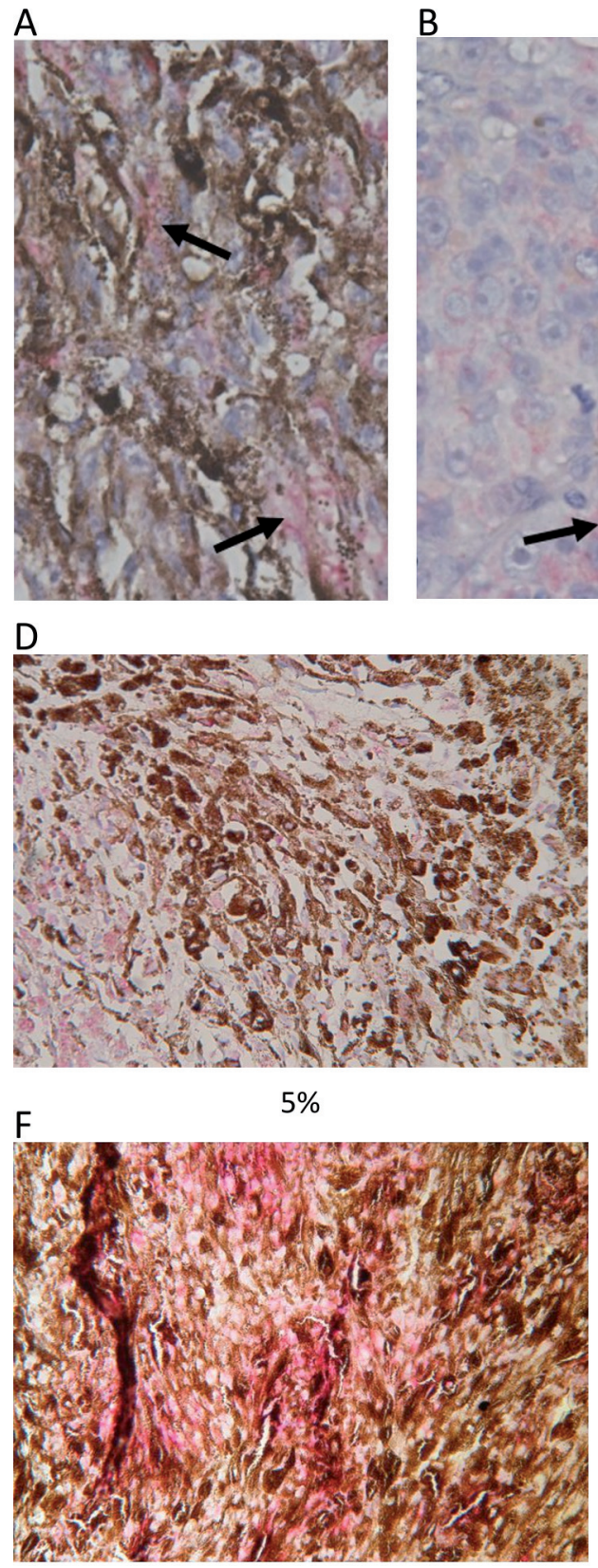

$40 \%$

B
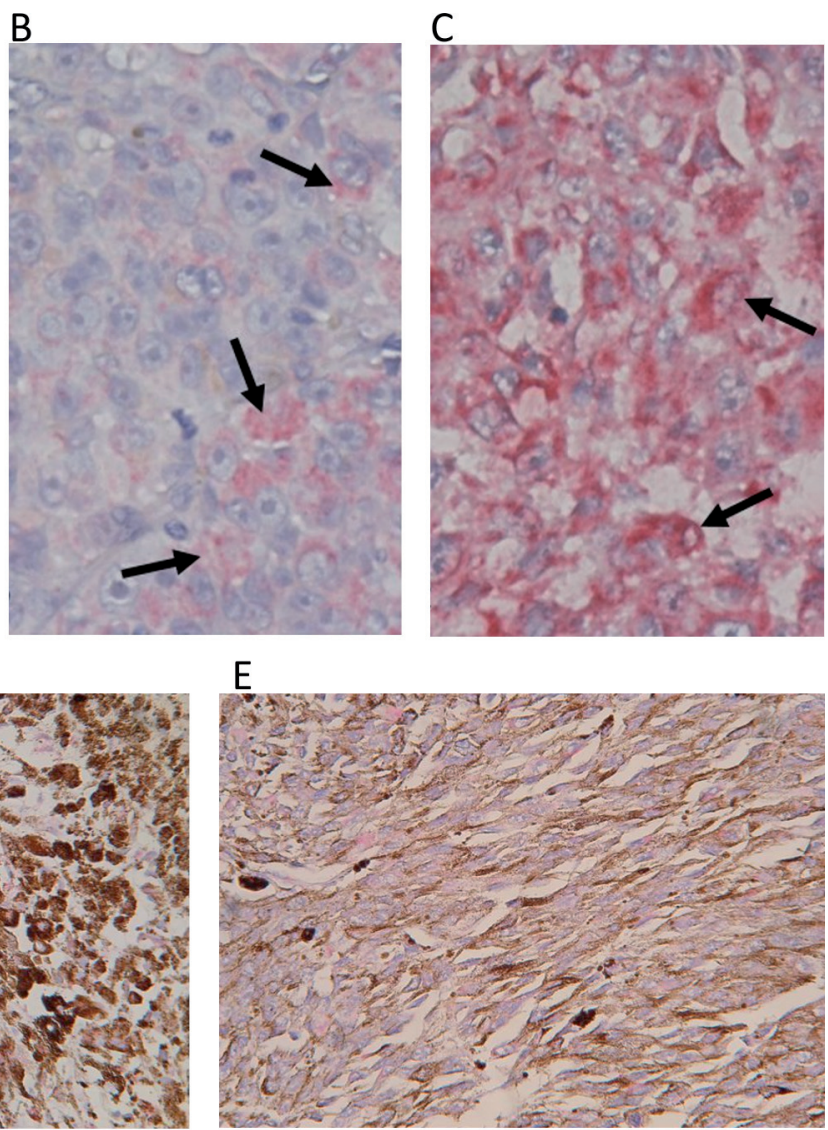

$\mathrm{G}$

$20 \%$

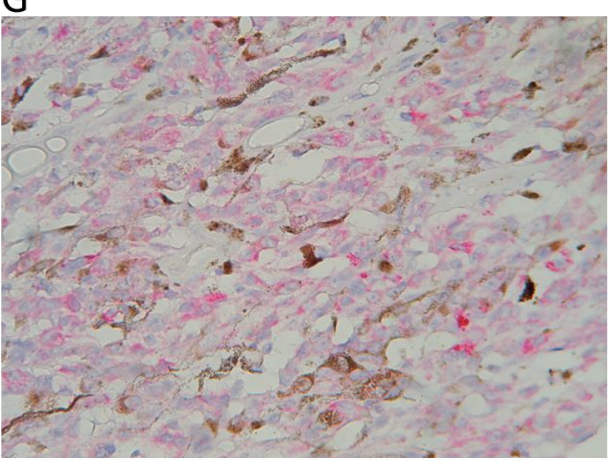

$100 \%$

Figure 1. AIF expression in uveal melanoma. Red color fine granular cytoplasmic positivity of weak (A), moderate (B) and strong (C) intensity. Immunoalkaline phosphatase, $400 x$.

Histological preparations showing different density of immunohistochemical reaction with antibodies against AIF. Immuno-alkaline phosphatase, 200x (D, E, F, G). 
years. Enucleation was performed in 48 patients, 5 patients had endoresection and one exenteration of the orbit. All patients had affected only one eye, in 23 patients (43\%) the right eye was affected. The tumor originated from choroid in 46 patients, from ciliary body in 6 patients and simultaneously from both the choroid and ciliary body in 2 patients. Information about the size of the tumor at the time of surgery was known in 42 patients (78\%). The average largest diameter of the tumor was $14.1 \mathrm{~mm}$ and the average tumor volume was $0.86 \mathrm{~cm}^{3}$. Based on the tumor size and the metastatic activity the disease was TNM classified into particular categories. At the time of surgery all patients were in the stage N0; there was one patient with M1 stage with developed metastases in lungs and the liver.

Histopathological findings of uveal melanoma were: spindle cell type B in $50 \%$, mixed type in $28 \%$, spindle cell type A in $11 \%$ and epithelioid type in $7 \%$. In two patients who underwent endoresection the tumor cell type was not possible to be classified. In the group of 54 patients, to the date of Aug 31 st 2012 with the average follow-up length of $61 \pm 35$ months (median 61 months), we registered death in 30 (56\%) patients. Death occurred in $42 \pm 27$ months after surgery (median 38 months).

Survival over 5-years was in $32(59 \%)$ patients. Distant metastases were found in $22(44 \%)$ patients. Most of the distant metastases were located in the liver- 20 patients $(91 \%)$ and in lungs- 5 patients ( $23 \%$ ) patients. In 7 patients ( $32 \%)$ more than one metastatic place were formed. Median of survival after metastasis discovery was 3 months.

Immunohistochemical analysis. Immunoreactivity of AIF was detected in $39(80 \%)$ evaluated tumors as fine granular cytoplasmic staining, no nuclear staining was detected. The first third of samples with AIF-immunoreactive cells reached the QS value of 4, which was then defined as the threshold for AIF positivity. In the whole group there was $33(67 \%)$ with QS $\geq 4$. Immunoreactivity of AIF was detected in variable percentage of tumor cells and in different intensities: weak in 10, moderate in 14 and strong in 12 patients (Fig. 1).

Confocal fluorescence microscopy confirmed the intracytoplasmic granular AIF positivity that colocalized with the granular structures labeled with the anti-mitochondrial antibody (Fig. 2). Colocalization of AIF red and mitochondrial green signals was highly significant in neoplastic cells when

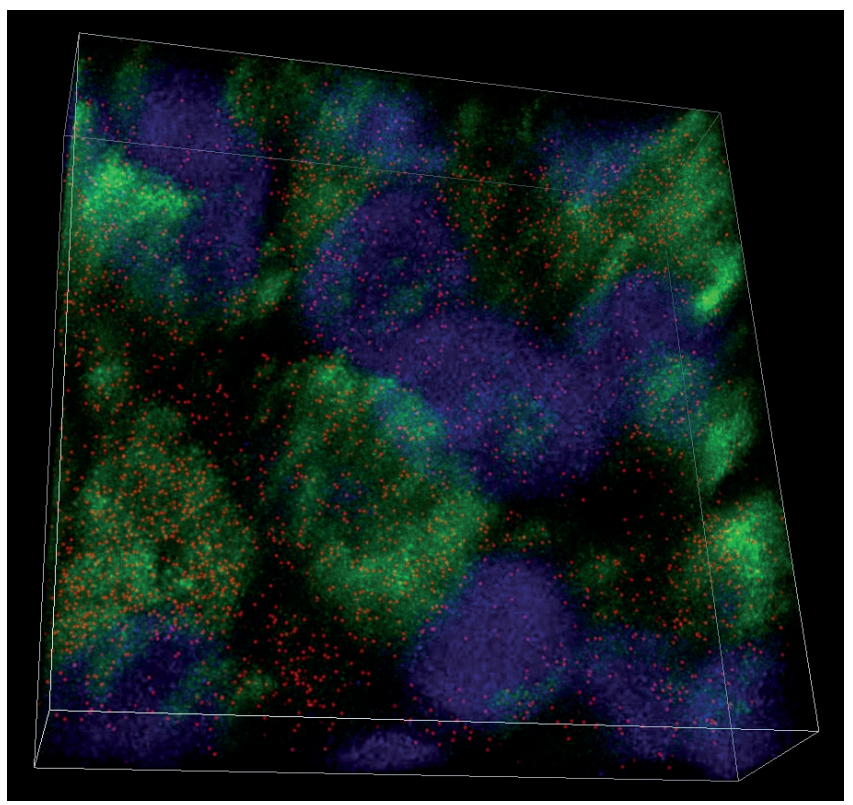

Figure 2. Confocal 3-dimensional imaging of AIF (red), anti-mitochondrial antibody (green) and nuclei labeled with DAPI (blue) in uveal melanoma tissue. Indirect fluorescence, 630x.

compared with vascular endothelium (not shown) as reference non neoplastic tissue. Manders' overlap coefficient k1 (red/ green) was 0.94 and $\mathrm{k} 2$ (green/red) was 0.17 [11].

Analysis of the evaluated risk factors and mortality. Immunohistochemical evaluation was performed in 49 patients; over 5-year survival had 28 (57\%) and less than 5 years survival $21(43 \%)$ patients. Comparison of the two groups pointed out the following statistically significant parameters: the size of the tumor, T stage of the tumor based on TNM classification and the cellular type of the tumor. Age, sex, side, anatomical location, nor infiltration of n. opticus, did not proof statistically significant difference between the compared groups (Tab. 1 and Tab. 2).

Comparison of the immunohistochemical evaluation of AIF expression in the group with favorable and less favorable prognosis is summarized in Tab. 3. The intensity of immunohistochemically detected expression of AIF, moderate and strong, also correlated with less favorable prognosis of patients.

Table 1. The cohort of patients included in the study. Comparison of basic demographic and clinical parameters between patients with different 5 years survival prognosis. Continuous parameters.

\begin{tabular}{|c|c|c|c|c|c|c|}
\hline \multirow{2}{*}{ Studied parameters } & \multicolumn{2}{|c|}{$\begin{array}{l}\text { Survival } \\
>5 \text { years }\end{array}$} & \multicolumn{2}{|c|}{$\begin{array}{l}\text { Survival } \\
<5 \text { years } \\
\end{array}$} & \multirow[b]{2}{*}{$P$} & \multirow[b]{2}{*}{$\mathbf{N}$} \\
\hline & Value range & $\begin{array}{c}\text { Average } \\
\pm \mathrm{MD}\end{array}$ & Value range & $\begin{array}{c}\text { Average } \\
\pm \mathrm{MD}\end{array}$ & & \\
\hline Age (years) & $25-87$ & $63 \pm 13$ & $28-84$ & $64 \pm 15$ & 0.942 & 54 \\
\hline Maximal tumour dimension (mm) & $6-21$ & $12.5 \pm 3.7$ & $9-24$ & $16.6 \pm 3.7$ & 0.001 & 42 \\
\hline Tumour volume $\left(\mathrm{cm}^{3}\right)$ & $0.06-2.47$ & $0.60 \pm 0.55$ & $0.14-5.02$ & $1.30 \pm 1.23$ & 0.026 & 42 \\
\hline
\end{tabular}

$\mathrm{N}=$ number of patients in whom we could analyze the parameter 


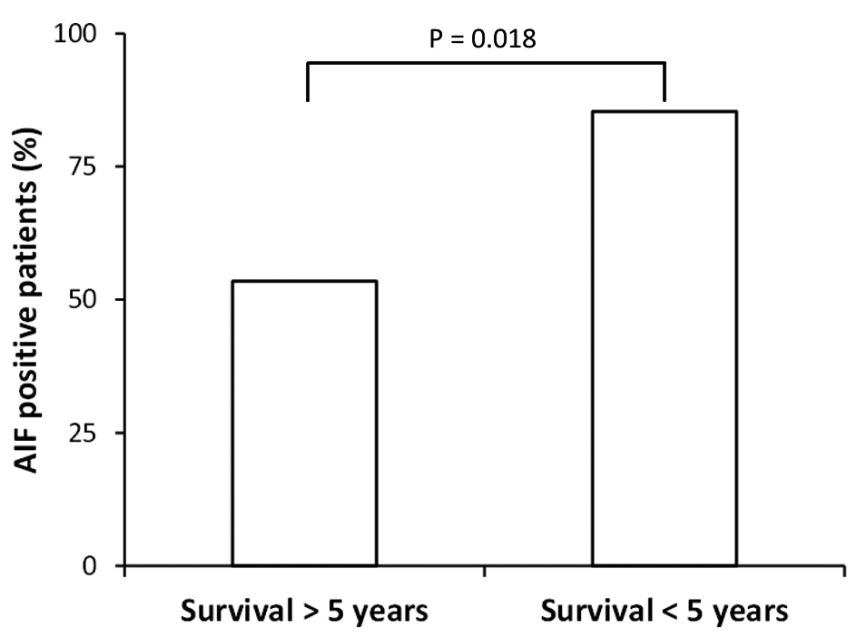

Figure 3. AIF positivity (Quick Score $\geq 4$ ) is significantly more frequent in patients with less than 5 years survival.

AIF positivity by itself, as defined above, was connected with shorter survival (Fig. 3). Statistically significantly higher 5-year mortality, in patients with AIF-positive tumor when compared to the rest of the patients, was indicated also by Kaplan-Meier survival analysis (Fig. 4).

\section{Discussion}

Information about prognosis is an important part of the clinical management of the patient with oncological disease [12]. Several clinical studies indicate the unequivocal need of identification of patients with less favorable prognosis by reliable prognostic factors [13-15]. In the present work we analyze some of the known prognostic factors and correlate

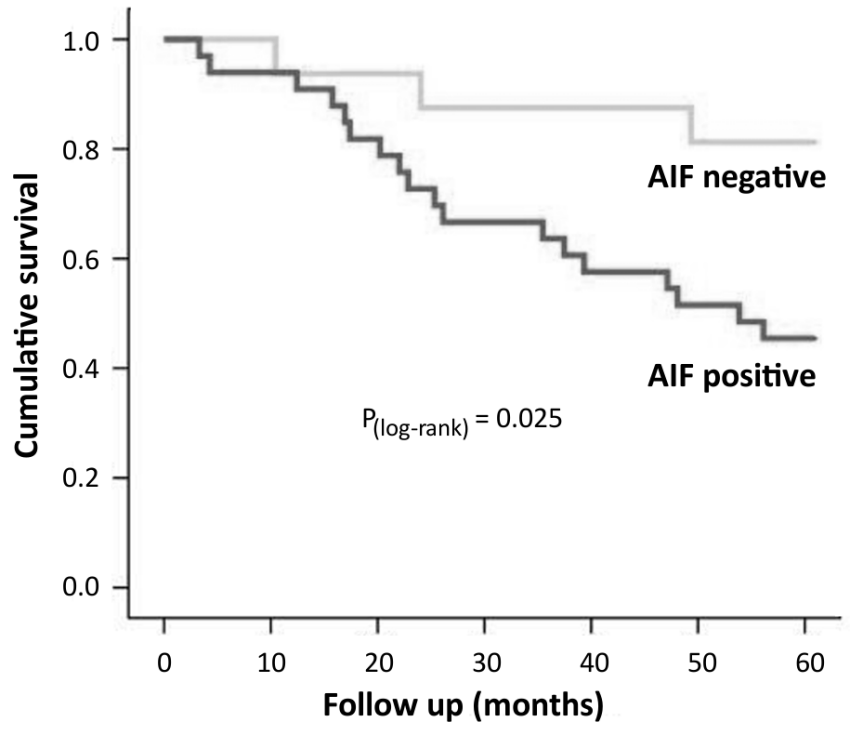

Figure 4. Kaplan-Meier analysis of survival separates the two groups of patients according to immunohistochemical detection of AIF (Quick Score $\geq 4$ ) in tumor cells.

them with the expression of AIF as a potential additional marker of biological potential of UM.

Basic characteristics of the presented pool of patients are comparable with those introduced in other published studies [16]. From among the clinical prognostic factors our results confirmed the negative prognostic value of the tumor size, " $\mathrm{T}$ " stage of the TNM classification and the mixed cytomorphological type of the neoplasm [17-20].

AIF is a ubiquitous protein with contending functions. The first function is proapoptotic in the nucleus. The second one

Table 2. The cohort of patients included in the study. Comparison of basic demographic and clinical parameters in patients with over and less than 5 years survival prognosis. Incontinuous parameters.

\begin{tabular}{|c|c|c|c|c|c|c|c|}
\hline \multirow[t]{2}{*}{ Studied parameters } & \multicolumn{2}{|c|}{$\begin{array}{l}\text { Survival } \\
>5 \text { years }\end{array}$} & \multicolumn{2}{|c|}{$\begin{array}{l}\text { Survival } \\
<5 \text { years }\end{array}$} & \multirow[t]{2}{*}{$P$} & \multirow{2}{*}{$\boldsymbol{P}_{\text {exact }}$} & \multirow[t]{2}{*}{ Odds Ratio } \\
\hline & $\%$ & $\mathbf{N}$ & $\%$ & $\mathbf{N}$ & & & \\
\hline Male & 44 & $14 / 32$ & 55 & $12 / 22$ & 0.435 & 0.580 & $1.54(0.52-4.60)$ \\
\hline Right eye & 44 & $14 / 32$ & 41 & $9 / 22$ & 0.836 & 1.000 & $0.89(0.30-2.67)$ \\
\hline Choroidal melanoma & 84 & $27 / 32$ & 86 & $19 / 22$ & 0.840 & 1.000 & $1.17(0.25-5.51)$ \\
\hline Ciliary body melanoma & 13 & $4 / 32$ & 9 & $2 / 22$ & 0.695 & 1.000 & $0.70(0.12-4.20)$ \\
\hline Ciliary body and choroidal melanoma & 3 & $1 / 32$ & 5 & $1 / 22$ & 0.786 & 1.000 & $1.48(0.09-24.93)$ \\
\hline Spindle cell type B melanoma & 77 & $23 / 30$ & 46 & $10 / 22$ & 0.021 & 0.040 & $0.25(0.08-0.84)$ \\
\hline Spindle cell type A melanoma & 20 & $6 / 30$ & 0 & $0 / 22$ & 0.026 & 0.033 & $0.52(0.40-0.69)$ \\
\hline Epithelioid melanoma & 10 & $3 / 30$ & 5 & $1 / 22$ & 0.466 & 0.629 & $0.43(0.04-4.42)$ \\
\hline Mixed cell melanoma & 13 & $4 / 30$ & 50 & $11 / 22$ & 0.004 & 0.006 & $6.50(1.70-24.93)$ \\
\hline Eye globe or optic nerve infiltration & 44 & $12 / 27$ & 41 & $9 / 22$ & 0.804 & 1.000 & $0.87(0.28-2.71)$ \\
\hline $\mathrm{T} 1$ or $\mathrm{T} 2$ stage & 65 & $17 / 26$ & 19 & $3 / 16$ & 0.003 & 0.005 & $0.12(0.03-0.54)$ \\
\hline T3 or T4 stage & 35 & $9 / 26$ & 81 & $13 / 16$ & 0.003 & 0.005 & $8.19(1.84-36.42)$ \\
\hline
\end{tabular}

$\mathrm{N}=$ number of positive cases for studied parameters / overall number of patients in subgroup, some of the studied parameters were not available in all patients 
Table 3. Immunohistochemical detection of AIF expression level in the two groups of patients with different 5 years survival prognosis.

\begin{tabular}{|c|c|c|c|c|c|c|c|}
\hline \multirow[t]{2}{*}{ Studied parameter } & \multicolumn{2}{|c|}{$\begin{array}{l}\text { Survival } \\
>5 \text { years }\end{array}$} & \multicolumn{2}{|c|}{$\begin{array}{l}\text { Survival } \\
<5 \text { years }\end{array}$} & \multirow[t]{2}{*}{$P$} & \multirow{2}{*}{$P_{\text {exact }}$} & \multirow[t]{2}{*}{ Odds Ratio } \\
\hline & $\%$ & $\mathbf{N}$ & $\%$ & $\mathbf{N}$ & & & \\
\hline AIF positive (QS $\geq 4)$ & 54 & $15 / 28$ & 86 & $18 / 21$ & 0.018 & 0.030 & $5.20(1.24-21.73)$ \\
\hline AIF immunoreactivity 3 & 14 & $4 / 28$ & 38 & $8 / 21$ & 0.055 & 0.092 & $3.69(0.93-14.63)$ \\
\hline AIF immunoreactivity 2 or 3 & 36 & $10 / 28$ & 76 & $16 / 21$ & 0.005 & 0.009 & $5.76(1.62-20.45)$ \\
\hline AIF immunoreactivity 2 & 21 & $6 / 28$ & 38 & $8 / 21$ & 0.201 & 0.222 & $2.26(0.64-7.96)$ \\
\hline AIF immunoreactivity 1 & 29 & $8 / 28$ & 10 & $2 / 21$ & 0.102 & 0.155 & $0.26(0.49-1.40)$ \\
\hline
\end{tabular}

$\mathrm{N}=$ number of positive cases for studied parameters / overall number of patients in subgroup, $\mathrm{QS}=$ quick score

is in mitochondria to provide the protective oxidoreductasis. This protein undergoes proteolysis after an apoptotic insult and it is translocated to nucleus to induce condensation of chromatin and DNA degradation. Survival of cells as well as cell death plays a significant role in oncogenesis. Experimental studies confirm that inhibition of AIF proapoptotic function participates at the chemoresistance in lung small cell carcinoma and colon cancer $[8,21]$. These necroptotic pathways, in which AIF is involved, can be regulated to a certain level, as it is presented in recent research [22, 23]. Interesting experimental data provide evidence that snake venom Lebein induces nuclear translocation of AIF in melanoma cell lineage in vitro leading to their apoptotic death [24]. It is evident that antiapoptotic mechanisms contribute to melanoma cells survival. Targeting of antiapoptotic factor Survivin induced caspases activation and nuclear translocation of AIF, leading to death in melanoma cell culture [25].

The limited availability of data about AIF cannot supply its potential in clinical practice. Immunohistochemically detected AIF occurrence has been reported in gastrointestinal tract tumors and in ameloblastomas [26-28]. These studies evaluated the cytoplasmic positivity which is bound to its protective function in the mitochondrial environment. Our study originally intended the evaluation of AIF incidence in the nucleus and its relevance in patient's prognosis. No AIF protein nuclear translocation was observed in the uveal melanomas, nevertheless, the cytoplasmic expression was an almost consistent finding. The results indicated the survival less than 5-years in patients with high level of AIF expression. When compared with patients with immunohistochemically detected low level of AIF, the survival was more than 5-years. This indicated that the biological potential of these tumors could be related to the function of mitochondrial AIF which is required for oxidative phosphorylation and energy generation. The consequence is the support of tumorigenic growth of cancer cells [29]. The statistical results of our study confirmed the significantly worse prognosis in patients with UM with high level of AIF which was documented also by Kaplan-Meier analysis (see Fig. 4). On the other hand, through its effect on $\beta$-catenin signaling, AIF inhibits epithelial-mesenchymal transition (EMT) and metastasis of cancer cells in vitro and in orthotopically implanted xenografts [30]. It is obvious that the role of AIF in the neoplastic cells must be post evaluated in the context of its various biological functions.

In conclusion, our work presents immunohistochemical evaluation of AIF expression as a new potential prognostic marker in patients with UM. This marker has a potential to gain higher significance in the future especially in connection with potential adjuvant therapies targeting modulators of the AIF.

Acknowledgements: We would like to appreciate excellent laboratory assistance of Mrs. Emilia Klincova. The project was supported by Comenius University Grant No: UK/204/2011 and KEGA-008$\mathrm{UK}-4 / 2014$.

\section{References}

[1] SINGH AD, TOPHAM A Survival rates with uveal melanoma in the United States: 1973-1997. Ophthalmology 2003; 5: 962-5. https://doi.org/10.1016/S0161-6420(03)00077-0

[2] GAMEL JW, MCLEAN IW, MCCURDY JB Biologic distinctions between cure and time to death in 2892 patients with intraocular melanoma. Cancer 1993; 7: 2299-305. https:// doi.org/10.1002/1097-0142(19930401)71:7<2299::AIDCNCR2820710721>3.0.CO;2-G

[3] FURDOVA A, STRMEN P, WACZULIKOVA I, CHORVATH M, SRAMKA M et al. One-day session LINAC-based stereotactic radiosurgery of posterior uveal melanoma. Eur J Ophthalmol 2012; 2: 226-235. https://doi.org/10.5301/ EJO.2011.7733

[4] TSCHENTSCHER F, HUSING J, HOLTER T et al. Tumor classification based on gene expression profiling shows that uveal melanomas with and without monosomy 3 represent two distinct entities. Cancer Res 2003; 63: 2578-2584.

[5] COUPLAND SE, LAKE SL, ZESCHNIGK M, DAMATO BE Molecular pathology of uveal melanoma. Eye 2013; 27: 230-242. https://doi.org/10.1038/eye.2012.255

[6] DELAVALLEE L, CABON L, GALAN-MALO P, LORENZO HK, SUSIN SA AIF-mediated caspase-independent necroptosis: a new chance for targeted therapeutics. IUBMB Life 2011; 4: 221-32. https://doi.org/10.1002/iub.432

[7] GALLEGO MA, JOSEPH B, HEMSTROM TH, TAMIJI S, MORTIER L Apoptosis-inducing factor determines the chemoresistance of non-small-cell lung carcinomas. 
Oncogene 2004; 37: 6282-91. https://doi.org/10.1038/ sj.onc. 1207835

[8] GASS JD Comparison of uveal melanoma growth rates with mitotic index and mortality. Arch Ophthalmol 1985; 7: 924 31. https://doi.org/10.1001/archopht.1985.01050070050028

[9] EDGE SB, BYRD DR, COMPTON CC, FRITZ AG, GREENE FL et al. Malignant melanoma of the uvea, 547-560. In: S. Edge, D.R. Byrd, C.C. Compton, A.G. Fritz, F.L. Greene, A. Trotti (Eds.), AJCC Cancer Staging Manual. New York: Springer 2010, p 648. ISBN 978-0-387-88440-0.

[10] MEGO M, CIERNA Z, SVETLOVSKA D, MACAK D, MACHALEKOVA $\mathrm{K}$ et al. PARP expression in germ cell tumours. J Clin Pathol 2013; 7: 607-12. https://doi.org/10.1136/jclinpath2012-201088

[11] MANDER EMM, VERBEEK FJ, ATEN JA Measurement of co-localisation of objects in dual-colour confocal images. J Microscopy 1993; 169: 375-382. https://doi.org/10.1111/ j.1365-2818.1993.tb03313.x

[12] FURDOVA A, OLAH Z. Nadory tkanivovych struktur ocnej gule, p 20-64. In: A. Furdova, Z. Olah (Eds.), Nadory oka a okolitych struktur, Akademicke nakladatelstvi CERM, Brno, 2010, pp 147. ISBN 978-80-7204-689-8.

[13] SINGH AD, TURELL ME, TOPHAM AK Uveal melanoma: trends in incidence, treatment, and survival. Ophthalmology 2011; 9: 1881-5. https://doi.org/10.1016/j.ophtha.2011.01.040

[14] VIRGILI G, GATTA G, CICCOLALLO L, CAPOCACCIA R, BIGGERI A et al. Survival in patients with uveal melanoma in Europe. Arch Ophthalmol 2008; 10: 1413-8. https://doi. org/10.1001/archopht.126.10.1413

[15] WORLEY LA, ONKEN MD, PERSON E, ROBIRDS D, BRANSON J et al. Transcriptomic versus chromosomal prognostic markers and clinical outcome in uveal melanoma. Clin Cancer Res 2007; 5: 1466-71. https://doi.org/10.1158/1078-0432. CCR-06-2401

[16] SINGH AD, BERGMAN L, SEREGARD S Uveal melanoma: epidemiologic aspects. Ophthalmol Clin North Am 2005; 1: 75-84. https://doi.org/10.1016/j.ohc.2004.07.002

[17] FLOCKS M, GERENDE JH, ZIMMERMAN LE The size and shape of malignant melanomas of the choroid and ciliary body in relation to prognosis and histologic characteristics; a statistical study of 210 tumors. Trans Am Acad Ophthalmol Otolaryngol 1955; 6: 740-58.

[18] MCLEAN IW, FOSTER WD, ZIMMERMANN LE Uveal melanoma: location, size, cell type, and enucleation as risk factors in metastasis. Hum Pathol 1982; 2: 123-32. https:// doi.org/10.1016/S0046-8177(82)80116-0

[19] SIMOES CC, CALL MK, CORREA ZM, SPAULDING AG, AUGSBURGER JJ Clinical and histopathological features and immunoreactivity of human choroidal and ciliary melano- mas as prognostic factors for metastasis and death. Graefes Arch Clin Exp Ophthalmol 2011; 12: 1795-803. https://doi. org/10.1007/s00417-011-1769-7

[20] FURDOVA A, SLEZAK P, CHORVATH M, WACZULIKOVA I, SRAMKA $M$ et al. No differences in outcome between radical surgical treatment (enucleation) and stereotactic radiosurgery in patients with posterior uveal melanoma. Neoplasma 2010; 4: 377-81.

[21] URBANO A, LAKSHMANAN U, CHOO PH, KWAN JC, NG $P Y$ et al. AIF suppresses chemical stress-induced apoptosis and maintains the transformed state of tumor cells. EMBO J 2005; 15: 2815-26. https://doi.org/10.1038/sj.emboj.7600746

[22] LIU H, SCHOLZ C, ZANG C, SCHEFE JH, HABBEL P et al. Metformin and the mTOR inhibitor everolimus (RAD001) sensitize breast cancer cells to the cytotoxic effect of chemotherapeutic drugs in vitro. Anticancer Res 2012; 5: 1627-37.

[23] WANG LJ, XIAO HW, BAI E, ZHOU X, LI M et al. Effect of the C-terminal truncated human apoptosis-inducing factor delta1-480 on biological behaviors of MCF-7 cells. Nan Fang Yi Ke Da Xue Xue Bao 2013; 9: 1285-8.

[24] HAMMOUDA MB, MONTENEGRO MF, SANCHEZ-DELCAMPO L, ZAKRAOUI O, ALOUI Z et al. Lebein, a Snake Venom Disintegrin, Induces Apoptosis in Human Melanoma Cells. Toxins 2016; 8(7): 206. https://doi.org/10.3390/toxins8070206

[25] LIU T, BROUHA B, GROSSMAN D Rapid induction of mitochondrial events and caspase-independent apoptosis in Survivin-targeted melanoma cells. Oncogene 2004; 23(1): 39-48. https://doi.org/10.1038/sj.onc. 1206978

[26] JEONG EG, LEE JW, SOUNG YH, NAM SW, KIM SH et al. Immunohistochemical and mutational analysis of apoptosisinducing factor (AIF) in colorectal carcinomas. APMIS 2006; 12: 867-73. https://doi.org/10.1111/j.1600-0463.2006. apm 502.x

[27] KUMAMOTO H, OOYA K Detection of mitochondria-mediated apoptosis signaling molecules in ameloblastomas. J Oral Pathol Med 2005; 9: 565-72. https://doi.org/10.1111/j.16000714.2005.00354.x

[28] LEE JW, JEONG EG, SOUNG YH, KIM SY, NAM SW et al. Immunohistochemical analysis of apoptosis-inducing factor (AIF) expression in gastric carcinomas. Pathol Res Pract 2006; 7: 497-501. https://doi.org/10.1016/j.prp.2006.03.004

[29] PORTER AG, URBANO AG Does apoptosis-inducing factor (AIF) have both life and death functions in cells? BioEssays 2006; 28: 834-843. https://doi.org/10.1002/bies.20444

[30] SHEN SM, GUO M, XIONG Z, YU Y, ZHAO XY et al. AIF inhibits tumor metastasis by protecting PTEN from oxidation. EMBO Reports 2015; 16: 1563-1580. https://doi. org/10.15252/embr.201540536 